\title{
Investigation of Power Quality Indices in Jordanian Distribution Grid
}

\author{
Eyad Almaita ${ }^{1}$ \\ ${ }^{I}$ (Electrical Power and Mechatronics Engineering Department, Engineering/Tafila Technical \\ University, Jordan)
}

\begin{abstract}
The sensitivity and the highly connected modern power systems make Power quality problems a priority in these systems. Both utilities and consumers have essential role in dealing with these problems. It is utilities responsibility to provide a clean and reliable power. On the other hand, it is consumer's responsibility to draw power with acceptable indices. In this Paper, the type of the consumer's facility is chosen as a basis for managing power quality indices. In this paper, comprehensive power quality in Jordan Low-Voltage Electrical Power Grid is measured. The loads are divided into five categories: : (i) industrial loads, (ii) commercial loads, (iii) hospital loads, (iv) residential loads, and (v) office loads. Assuming each category will affect the grid in similar way, which will facilitate prediction of power quality problems. Also, this methodology will help proposing new regulation that governs the relation between utilities and consumers. The power quality indices considered in this paper are; THD, Crest factor, K-factor, Power factor, Harmonic to active power ratio, Voltage imbalance, and Frequency variations. The results show similar results for the loads with the same type. Also, the results show the correlation between the current total harmonic distortion and utility voltages and neutral-to-ground voltage, and between voltage and current imbalance.
\end{abstract}

Keywords: Power quality, Indices, harmonics, distribution grid, Jordan.

\section{Introduction}

Recently, Power quality issues attracted more attention from both utilities and electrical power consumers. This attention is driven by several factors; the proliferation of nonlinear loads in power system, the increasing sensitive load equipment to supply variation, , customers awareness about power quality problems, and the probability of failure impact magnification because of network interconnection. A suitable definition of power quality problem could be any variation of voltage, current, and/or frequency that can cause failure or misoperation of electrical equipment [1].

The literature contains many publications contain proposed indices to characterize the power quality for a given site or in the electrical grid. These indices include individual harmonics, total harmonic distortion, flicker, voltage and current imbalance, slow voltage variation, frequency deviation, power factor, and mains signaling [2]-[5]. While standards and many publication measure and tackle each of power quality problems alone[2], [6]-[9], other literature tried to formulate a parameter that combine two or more power quality problems in one index [10][11]. The power quality index for a given site can be specified by two types of measurements: (i) short-term measurements which are used to identify the disturbances in the power signals. The time window for this short-term measurements is 10(12) cycles depending on the frequency of supply 50 $\mathrm{Hz}$ or $60 \mathrm{~Hz}$, respectively[12], [13]. (ii) long-term measurements which are used to obtain statistical power quality indices[14], [15]. Till now no benchmark approach is adopted for managing power quality. While most regulatory ask utilities to comply with national or international standards within a given margin, many see the managing of the power quality should be done by deep collaboration between the customers and utilities[16][18]. This paper proposes the type of the customer facility as a basis for managing power quality indices. This paper is a continuation of the work presented in [19]. That work focused on just the harmonic index. In this paper a comprehensive power quality indices is measured and analyzed. This paper is organized as following: section II deal with problem formulation and research methodology. Section III is about results and discussion. Conclusions and findings are discussed in section IV.

\section{Problem Formulation and Methodology}

The power quality assessment in power system includes many indices such as transients, short-term duration variation, long-term duration variation, imbalance, waveform distortion, voltage fluctuation, and frequency variation [7]. The interaction between the consumer's loads and the grid power quality indices is always a controversial issue. This paper is proposed a simple methodology to assess the correlation between consumer's loads and power quality indices. The proposed method classifies the consumers into finite classes. This classification is based on the load category, assuming each load category will mostly have the same types 
of loads, and these loads will affect the grid power quality indices in similar way (i.e. inject approximately the same harmonic pollution type into the grid).

This paper classifies the loads into five distinct load categories: (i) industrial loads, (ii) commercial loads, (iii) hospital loads, (iv) residential loads, and (v) office loads.

The power quality indices used in this paper include: total harmonic distortion (voltage and current), crest factor (voltage and current), K-factor, harmonic power percentage, frequency fluctuation, and power factor.

1. Definitions of measured parameters:

- Fundamental frequency: Refers to the power source frequency which is usually $50 \mathrm{~Hz}$ or $60 \mathrm{~Hz}$.

- Total Harmonic Distortion (THD): The ratio of the root-square for the sum of the square values of all the harmonics to the root-mean-square (rms) value of the fundamental component[6][20] .

Where :

$$
\begin{gathered}
\text { THD }_{V}=\frac{\sqrt{\sum_{n=2}^{\infty} V_{n}^{2}}}{V_{1}} * 100 \% \\
T H D_{I}=\frac{\sqrt{\sum_{n=2}^{\infty} I_{n}^{2}}}{I_{1}} * 100 \%
\end{gathered}
$$

$\mathrm{n}=$ the harmonic order

$\mathrm{THD}_{\mathrm{V}}=$ the voltage total harmonic distortion

$\mathrm{THD}_{\mathrm{I}}=$ the current total harmonic distortion

$\mathrm{V}_{1}=$ the voltage fundamental component.

$\mathrm{I}_{1}=$ the current fundamental component.

$\mathrm{V}_{\mathrm{n}}=$ the $\mathrm{n}^{\text {th }}$ voltage harmonic.

$\mathrm{I}_{\mathrm{n}}=$ the $\mathrm{n}^{\text {th }}$ current harmonic.

- Voltage imbalance: is defined as the ratio of the negative sequence component magnitude to the positive sequence component magnitude in a three-phase system, expressed as a percentage[7].

Where:

$$
\text { Imbalance } \%=\frac{\left|V_{\text {neg }}\right|}{\left|V_{\text {pos }}\right|} * 100 \%
$$

$V_{\text {neg }}, V_{\text {pos }}$ are the negative and positive sequence components, respectively.

- Frequency Fluctuation: is the difference between the grid fundamental frequency and its specified nominal value (e.g. $50 \mathrm{~Hz}$, or $60 \mathrm{~Hz}$ ) [7].

- Crest Factor: The ratio of the peak (max) value (Yp) to the rms value (Yrms) [21].

$$
\text { Crest factor }=\frac{Y_{P}}{Y_{r m s}}
$$

- K-Factor: is an indication to the transformer capability to dissipate thermal losses under no-sinusoidal current [22]. It can be defined as:

$$
K-f a c t o r=\frac{\sum_{n=1}^{n_{\max }}\left(n I_{n}\right)^{2}}{\sum_{n=1}^{n_{\max }}\left(I_{n}\right)^{2}}
$$

- Active Phase Power: $\quad \frac{1}{N} \sum_{n=k}^{k+N} V_{x}(n) \cdot I_{x}(n)$

- Total Active Power for Y connection: $\boldsymbol{P}_{\text {total }}=\boldsymbol{P}_{\boldsymbol{A}}+\boldsymbol{P}_{B}+\boldsymbol{P}_{C}$

- Total Harmonic Power $=\sqrt{\mathbf{S}-\mathbf{S}_{1}}$

where

$S$ is the apparent power, $\mathrm{S}_{l}$ is apparent power for the fundamental component

- $\quad$ System power factor $\mathrm{Y}$ and $\Delta: \mathrm{PF}=\mathrm{P} / \mathrm{S}$

2. Data collection and analysis scheme

The methodology of this paper includes:

1. Collecting the Data through field measurements for the major power quality indices

The data collecting is performed as follows:

A. At first four cities are chosen these cities consume the major portion of electrical power in Jordan , the proposed cities are characterised as:

- 1(Amman): represents the city with the highest number of population

- City\#2 (Karak): represents the city that includes some bulky consumers

- City\#3 (Tafila): represents a city that contains an installed renewable energy projects. 
- City\#4 (Zarqa): represents the city with industrial base.

B. Different locations at each city are chosen in order to measure the major power quality indices. These locations will include industrial facilities, malls, residential buildings, and governmental buildings, etc. Some of these measurements are shown in Fig.1

C. Three-Phase Power recorder is used to carry out the measurements. These measurements will be through different times, days, months, and years.

2. Statistical techniques are used for data analysis. The data analysis will show the following:

A. The power quality indices considered in this paper are:

i. THD

ii. Crest factor

iii. K-factor

iv. Power factor

v. Harmonic to active power ratio

vi. Voltage imbalance

vii. Frequency variations

B. The average values are calculated as

i. All the samples from the same category (i.e. commercial loads) will be combined to form one big file including all collected measurements.

ii. The sample average is calculated as:

Where $x(i)$ is the $\mathrm{i}^{\text {th }}$ sample and $\mathrm{N}$ is the number of samples.

$$
\text { Average }=\frac{\sum_{i=0}^{N} \mathrm{x}(\mathrm{i})}{N}
$$
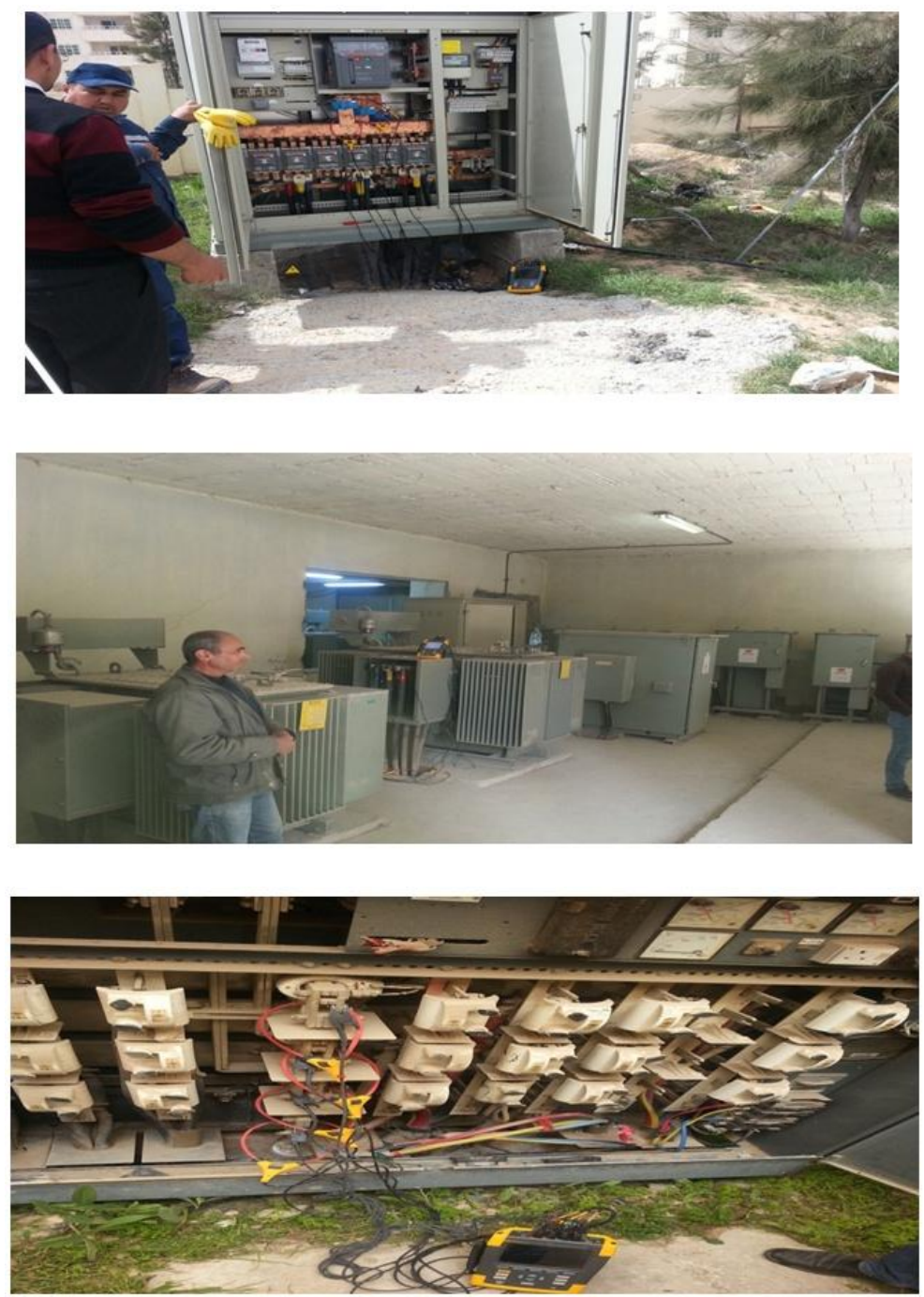


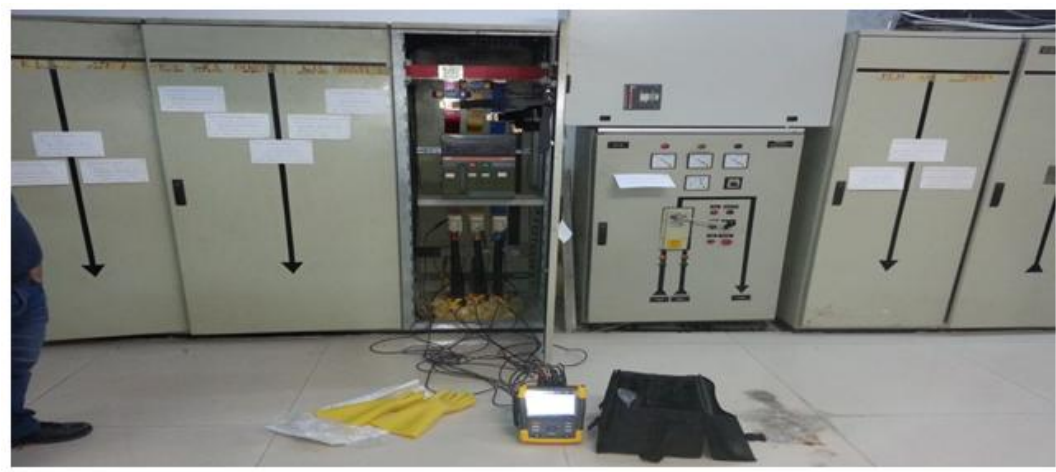

Fig. 2 Some of Cites Measurements

\section{Indentations and Equations (11 Bold)}

All the measurements in this research is carried out by Fluke 435-II/437-II Three Phase Energy and Power Quality Analyzer.

All the harmonic analysis is based on FFT algorithm. The FFT algorithm in accordance with IEC 610004-7 is used to calculate the fundamental and harmonic components of each input signal over a 10 cycle (50 Hz) time window.

Table 1 shows the average voltage THD values for each load category and for the four cities. Each value represents the average of the three phase THD values. For the recorded loads all the average values are within the ranges of IEEE Std. 519-1992. Table 2 shows the average current THD values for each load category and for the four cities. The first note about these data is that a lot of these values exceed the 5\% THD limit in IEEE Std. 519-1992. The industrial sector has the highest THD average value for the four cities, which is normal due to the extensive use of motor drive converters and Arc furnaces. The Office sector, which includes a lot of computer loads, CFL, and LED lighting, comes second. The commercial sector, has an interesting results. Cities \#1 and \#4 have similar results while cities \#2 and \#3 have similar results but they are relatively far from each other. This can be explained by the nature of these cities. Cities \#1 and \#4 are modern cities and include a lot of big malls, which have many nonlinear loads such as escalators and LEDs. On the other hand cities \#2 and \#3 are rural areas and have only small to medium shops.

Table 3 and Table 4 show the average crest-factor values for the voltage and current, respectively. The Ideal value for a crest factor is 1.414 , which represent a pure sinusoidal signal. While most of the measured voltage crest-factor values are close to the ideal value by \pm 0.1 , the current crest-factor values are above this ideal value. This indicates a deformation in the current waveform and a higher peak values comparing to the rms values, which can affect normal power supplies.

Table 1 Average phase voltage THD

\begin{tabular}{|l|l|l|l|l|}
\hline \multicolumn{5}{|l|}{ Voltage THD \% } \\
\hline & City\# 1 & City\# 2 & City\# 3 & City\# 4 \\
\hline Comm. & 1.335 & 1.991 & 1.462 & 0.826 \\
\hline Office & 1.304 & 1.177 & 1.174 & 1.532 \\
\hline Hosp. & 1.651 & 1.071 & 1.117 & 1.637 \\
\hline Indus. & 1.180 & 1.906 & 4.279 & 1.884 \\
\hline Resid. & 1.334 & 0.938 & 1.619 & 1.701 \\
\hline
\end{tabular}

Table 2 Average phase current THD

\begin{tabular}{|l|l|l|l|l|}
\hline \multicolumn{5}{|l|}{ Current THD \% } \\
\hline & City\# 1 & City\# 2 & City\# 3 & City\# 4 \\
\hline Comm. & 7.080 & 4.228 & 4.327 & 7.049 \\
\hline Office & 6.458 & 11.094 & 1.148 & 5.545 \\
\hline Hosp. & 6.531 & 5.336 & 4.763 & 6.176 \\
\hline Indus. & 7.908 & 3.882 & 6.536 & 6.824 \\
\hline Resid. & 6.536 & 5.691 & 4.842 & 4.593 \\
\hline
\end{tabular}

Table 3 Average phase voltage crest factor

\begin{tabular}{|l|l|l|l|l|}
\hline \multicolumn{5}{|l|}{ Voltage Crest Factor (Average) } \\
\hline & City\# 1 & City\# 2 & City\# 3 & City\# 4 \\
\hline Comm. & 1.422 & 1.410 & 1.410 & 1.425 \\
\hline Office & 1.394 & 1.420 & 1.396 & 1.397 \\
\hline Hosp. & 1.408 & 1.407 & 1.392 & 1.409 \\
\hline Indus. & 1.398 & 1.421 & 1.423 & 1.453 \\
\hline Resid. & 1.400 & 1.397 & 1.403 & 1.394 \\
\hline
\end{tabular}


Table 4 Average phase current crest factor

\begin{tabular}{|l|l|l|l|l|}
\hline \multicolumn{5}{|l|}{ Current Crest Factor (Avearge) } \\
\hline & City\# 1 & City\# 2 & City\# 3 & City\# 4 \\
\hline Comm. & 1.483 & 1.512 & 1.487 & 1.457 \\
\hline Office & 1.403 & 1.430 & 1.516 & 1.494 \\
\hline Hosp. & 1.625 & 1.568 & 1.452 & 1.475 \\
\hline Indus. & 1.402 & 1.548 & 1.440 & 1.669 \\
\hline Resid. & 1.570 & 1.503 & 1.550 & 1.490 \\
\hline
\end{tabular}

Table 5 shows the average $\mathrm{K}$-factor for the three phase currents. It indicates that most values are exceeding the value for a linear load, which is one. These measured values can help the utilities in systematic dating of their working transformers. The measured line frequency is shown in Table 6 . These values show the stability of frequency in Jordanian power grid. The standard deviation for these values is equal or les 0.1 . the consistency in frequency in power system is essential for the stability of these systems. Also, this value defined the fundamental frequency. Any deviation from this nominal value will affect many of the equipment connected to the grid. Voltage imbalance is shown in Table 7. All the measured voltage is within the standards limits, which limit the voltage imbalance to $2 \%$ in the PCC. The excessive voltage imbalance can cause motors overheating and can worsen the current imbalance problem.

Table 5 Average phase voltage K-factor

\begin{tabular}{|c|c|c|c|c|}
\hline \multicolumn{5}{|c|}{ Current K-Factor (Avearge) } \\
\hline & City\# 1 & City\# 2 & City\# 3 & City\# 4 \\
\hline Comm. & 1.614 & 1.062 & 1.073 & 1.033 \\
\hline Office & 1.050 & 1.158 & 1.312 & 1.103 \\
\hline Hosp. & 1.261 & 1.262 & 1.362 & 1.158 \\
\hline Indus. & 1.042 & 1.471 & 1.030 & 2.045 \\
\hline Resid. & 1.447 & 1.070 & 1.120 & 1.051 \\
\hline
\end{tabular}

Table 6 Frequency

\begin{tabular}{|l|l|l|l|l|}
\hline Frequency & City\# 1 & City\# 2 & City\# 3 & City\# 4 \\
\hline Comm. & 49.955 & 50.056 & 50.067 & 49.847 \\
\hline Office & 50.122 & 50.002 & 49.956 & 49.766 \\
\hline Hosp. & 50.057 & 50.078 & 50.054 & 49.793 \\
\hline Indus. & 49.952 & 49.986 & 50.045 & 50.073 \\
\hline Resid. & 49.968 & 49.813 & 50.003 & 50.044 \\
\hline
\end{tabular}

Table 7 Voltage imbalance

\begin{tabular}{|l|l|l|l|l|}
\hline \multicolumn{5}{|l|}{ Voltage imbalance \% } \\
\hline & City\# 1 & City\# 2 & City\# 3 & City\# 4 \\
\hline Comm. & 0.620 & 0.305 & 0.534 & 0.679 \\
\hline Office & 0.385 & 0.253 & 0.508 & 0.886 \\
\hline Hosp. & 0.302 & 0.305 & 0.371 & 0.507 \\
\hline Indus. & 0.353 & 0.581 & 0.431 & 0.359 \\
\hline Resid. & 0.375 & 0.320 & 0.304 & 0.217 \\
\hline
\end{tabular}

Table 8 shows the average power factor. As expected the residential loads have the highest power factor, since most of these loads are not highly inductive. The industrial loads have the lowest values. One important note that the power factor does not depend only on the inductive loads, also highly non-linear load could affect the power factor and this explain the low power factor for the commercial load in city\#4 . Another important aspect of power quality indices is shown in table 9 which represent the ratio between the total harmonic power and the total active power as percentage. It is well known that the useful power is that obtained from the fundamental component, while the harmonic power is not useful and can cause problems such as motor and transformers overheating.

Table 8 Average power factor

\begin{tabular}{|l|l|l|l|l|}
\hline \multicolumn{5}{|l|}{ Power Factor (average) } \\
\hline & City\# 1 & City\# 2 & City\# 3 & City\# 4 \\
\hline Comm. & 0.659 & 0.971 & 0.889 & 0.899 \\
\hline Office & 0.897 & 0.867 & 0.812 & 0.900 \\
\hline Hosp. & 0.861 & 0.916 & 0.874 & 0.969 \\
\hline Indus. & 0.791 & 0.894 & 0.842 & 0.850 \\
\hline Resid. & 0.918 & 0.905 & 0.945 & 0.920 \\
\hline
\end{tabular}


Table 9 Ratio between total harmonic power to total active power

\begin{tabular}{|l|l|l|l|l|}
\hline Total Harmonic Power/ Total Active Power \% \\
\hline & City\# 1 & City\# 2 & City\# 3 & City\# 4 \\
\hline Comm. & 0.056 & 0.060 & 0.176 & 0.020 \\
\hline Office & 0.083 & 0.089 & 0.060 & 0.057 \\
\hline Hosp. & 0.050 & 0.082 & 0.018 & 0.030 \\
\hline Indus. & 0.119 & 0.138 & 0.084 & 0.140 \\
\hline Resid. & 0.038 & 0.077 & 0.101 & 0.080 \\
\hline
\end{tabular}

The interaction between the current harmonics and the grid voltages are also investigated. The most correlation is found between the load current and the voltage between neutral-to-ground. Fig. 2 shows the THD level in the phase A current and THD level in neutral-to-ground voltage for a hospital load. The figure shows measured THD over one week period. The correlation coefficient between THD in Phase current and THD in neutral-to-ground voltage is 0.505 comparing to 0.1187 between THD for phase current and phase voltage. The correlation factor is 0.005 between the phase current and neutral current. A similar correlation factors are found for other load types. Another interesting finding is shown in Fig.3 which is the periodicity in the THD level in the phase voltages.Fig. 3 shows the THD level in the phase voltages for the three phases. This THD is for hospital load and is measured over one week period.
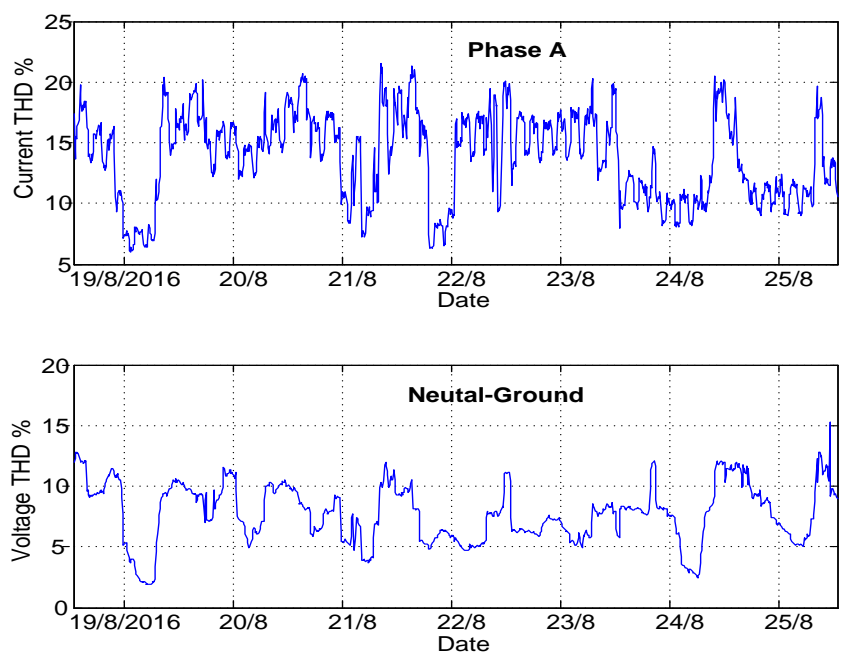

Fig.3 THD level in the phase A current (upper) and THD level in neutral-to-ground voltage (Lower) for a hospital load
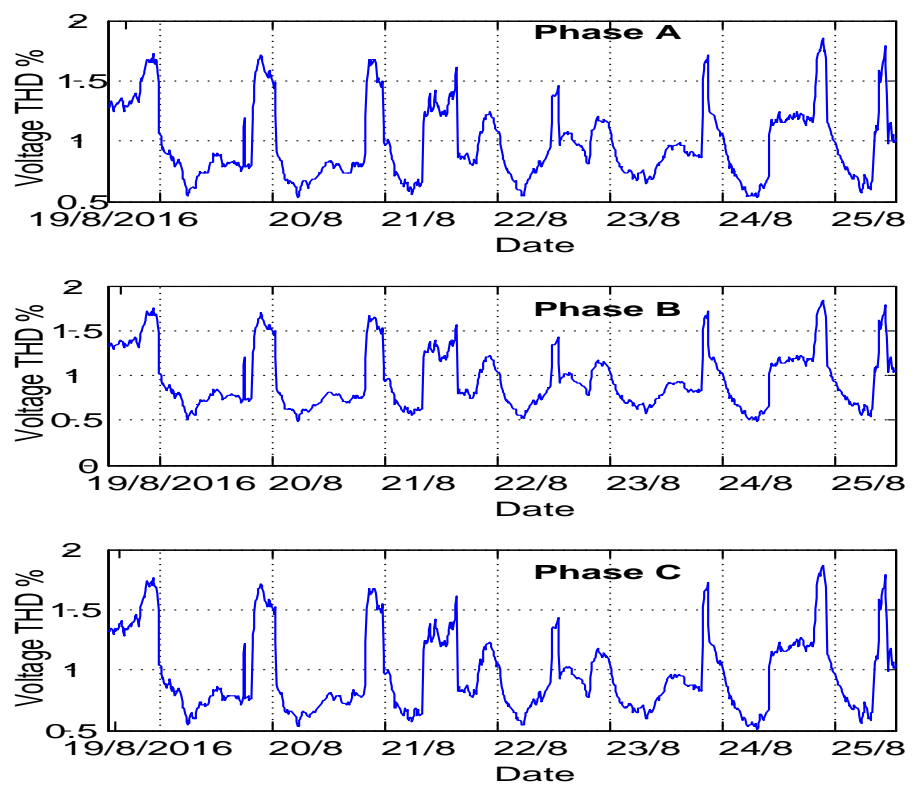

Fig.4 Time evolution for THD of the three phase voltages 
Fig. 4 shows the relation between the voltage and current imbalance. The upper part represents the normalized voltage and current imbalances that are calculated as the ratio between the negative and positive sequences. The lower part represents the normalized voltage and current imbalances that are calculated as the ratio between the zero and positive sequences. The correlation factors between the voltage and current imbalance is 0.7242 for the lower part comparing to 0.1241 to the lower part.
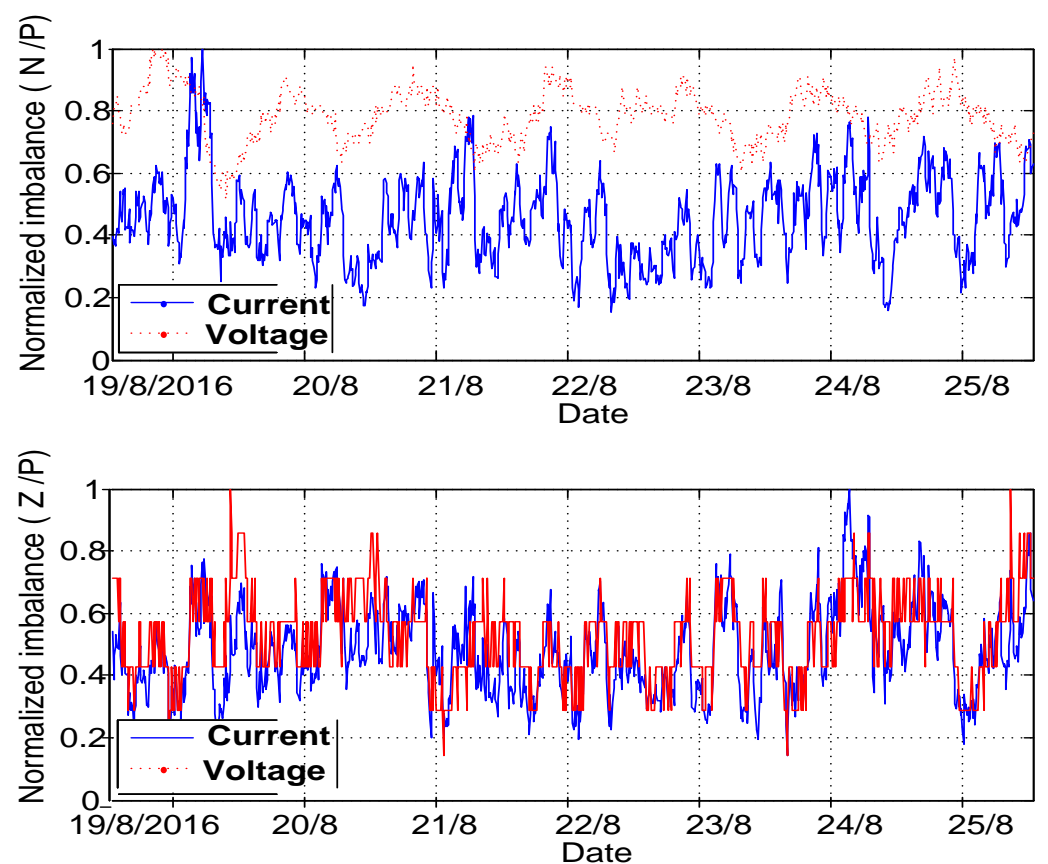

Fig. 5 Normalized voltage (solid) and current (dashed) imbalnce.

\section{Conclusion}

In this Paper, power quality indices in Jordanian low-voltage power grid are investigated. Field measurements for the major electrical units in JLVEPG are carried out for different locations in multiple cities. These measurements are followed by extensive data analysis techniques in order to identify THD, Crest factor, K-factor, Power factor, Harmonic to active power ratio, Voltage imbalance, and Frequency variations. The electrical loads were categorized into five sectors which are: commercial, governmental, hospital, industrial, and residential. The results show similar results for the loads with the same type. Also, the results show high correlation between the current total harmonic distortion and utility neutral-to-ground voltage. Also, the results show the interaction between voltage and current imbalance. This paper can be used as a basis for developing new regulations that govern the relation between the utilities and the consumers.

\section{Acknowledgements}

This research was supported by Scientific Research Support Fund (SRSF) in Jordan.

\section{References}

[1] K. L. Koo and Z. Emin, "Comparative Evaluation of Power Quality Modelling Approaches for Offshore Wind Farms," pp. 1-7.

[2] M. J. Ortega, J. C. Hern??ndez, and O. G. Garc??a, "Measurement and assessment of power quality characteristics for photovoltaic systems: Harmonics, flicker, unbalance, and slow voltage variations," Electr. Power Syst. Res., vol. 96, pp. 23-35, 2013.

[3] S. Yan, S.-C. Tan, C. K. Lee, B. Chaudhuri, and S. Y. Hui, "Use of Smart Loads for Power Quality Improvement," IEEE J. Emerg. Sel. Top. Power Electron., vol. 6777, no. c, pp. 1-1, 2016.

[4] A. Ferrero, "Measuring electric power quality: Problems and perspectives," Measurement, vol. 41, pp. 121-129, 2008.

[5] N. Gupta, A. Swarnkar, and K. R. Niazi, "Distribution network reconfiguration for power quality and reliability improvement using Genetic Algorithms," Int. J. Electr. Power Energy Syst., vol. 54, pp. 664-671, 2014.

[6] B. S. Publication, "Internationale International Standard Internationale International Standard,” vol. $2009,2000$.

[7] IEEE and Institute of Electrical and Electronic Engineers, IEEE Std 1159 - IEEE Recommended Practice for Monitoring Electric Power Quality., vol. 2009, no. June. 2009.

[8] H. Al Riyami, A. Al Busaidi, A. Al Nadabi, M. Al Siyabi, O. H. Abdalla, K. Al Manthari, B. Hagenkort, S. Mirza, and R. Fahmi, "Power Quality of Dhofar Network with 50 MW Wind Farm Connection," 2016.

[9] B. Stridh and J. Rosenlind, "Power quality experiences from Sweden $€^{\mathrm{TM}} \mathrm{s}$ first MW photovoltaics park and impact on LV planning," pp. 3-8, 2016.

[10] S. Jo, S. Son, and J. Park, “On Improving Distortion Power Quality Index in Distributed Power Grids,” vol. 4, no. 1, pp. 586-595, 2013.

[11] A. Russo and P. Verde, "Site and System Indices for Power-Quality Characterization of Distribution Networks With Distributed 
Generation," vol. 26, no. 3, pp. 1304-1316, 2011.

[12] K. Thirumala, T. Jain, and A. C. Umarikar, "Visualizing time-varying power quality indices using generalized empirical wavelet transform," Electr. Power Syst. Res., vol. 143, pp. 99-109, 2017.

[13] N. Mu, J. C. Alfonso-gil, S. Orts-grau, S. Seguí-chilet, and F. J. Gimeno-sales, "Instantaneous approach to IEEE Std . 1459 power terms and quality indices," vol. 125, pp. 228-234, 2015.

[14] J. Barros and R. I. Diego, "A review of measurement and analysis of electric power quality on shipboard power system networks," Renew. Sustain. Energy Rev., vol. 62, pp. 665-672, 2016.

[15] D. D. Ferreira, J. M. De Seixas, A. S. Cerqueira, C. A. Duque, M. H. J. Bollen, and P. F. Ribeiro, "A new power quality deviation index based on principal curves," Electr. Power Syst. Res., vol. 125, pp. 8-14, 2015

[16] J. Rens, "The Application of Modern Technology in Power Quality Management," 2009.

[17] J. Rens, "On the development of a Power Quality Benchmarking model," 2009 10th Int. Conf. Electr. Power Qual. Util. EPQU'09, 2009

[18] R. Chiumeo, M. De Nigris, C. Gandolfi, L. Garbero, and L. Tenti, “indices at national and macro area level,” pp. 0-6, 2010.

[19] E. Almaita, "Harmonic Assessment in Jordanian Power Grid Based on Load Type Classification,” vol. 11, pp. 58-64, 2016.

[20] S. M. Ieee, IEEE Recommended Practices and Requirements for Harmonic Control in Electrical Power Systems IEEE Recommended Practices and. 1992.

[21] E. Engineers, Powering and G rounding E l e c t ronic E q u i p m e $n t$, vol. 2005. 2005.

[22] C. M. De Brito, P. Van Rhyn, and S. Africa, "The Use of Power Quality Standards to Establish an Equivalent Transformer Capability Under Harmonic Loading,” 2016. 